UDK: 821.163.41.09-31 Тасић В.

\title{
- KONSTRUKT URBANOG U ROMANU KIŠA I HARTIJA VLADIMIRA TASIĆA
}

\author{
ANA VUKMANOVIĆ 1 \\ Zadužbina Ilije M. Kolarca, \\ Beograd, Srbija
}

U romanu Kiša i hartija obrazuje se kulturni i estetski konstrukt grada. Odnosi likova prema urbanom prostoru pokazuju kako taj prostor utiče na formiranje njihovih identiteta. Oni zauzimaju pozicije unutar kontrastnih odnosa svoje/tuđe, kao i staro/novo. Urbani konstrukt se formira i u međusobnoj komunikaciji između junaka, kao i u njihovim unutrašnjim preispitivanjima. Značaj kretanja za slike grada obeležen je parovima otvoreno/zatvoreno i, posebno, centar/periferija. Egzistencijalni sloj značenja prati pojave urbanih predstava, posebno one vezane za performans Klio $i$ Trepsihora, u kom se spajaju ritam grada i egzistencijalni krik čoveka. Vizuelni nivo performansa uključuje se u promišljanje problema prava na grad.

Ključne reči: grad, konstrukt, performans, komunikacija, identitet.

Razmišljajući o gradskom magacinu, pri početku Kiše i hartije, junakinja romana Tanja primećuje: „Za mene, to mesto kojim su slobodno šetali psi i mačke, beskućnici, bilo je stvarno (u to nema sumnje), ali je bilo i metafora. Projekcija, neko bi rekao" (Tasić 2004: 22). Upravo ta osobena pozicija prostora u ovom romanu upućuje na razmišljanje o konstruisanju predstave urbanog. Tasićev Novi Sad je fragmentarni prostor sećanja junaka, kao i stvarni grad sa kojim se oni sučeljavaju. Spajajući dva nivoa postojanja, on je „poprište nečeg drugog, nekog drugog, nekog drugog mesta” (Krauč 2002: 227). To drugo su i drugi ljudi, i različiti društveno-istorijski trenuci, i oni drugi što se nalaze u samim junacima, gde se sukobljavaju, prelivaju i razdvajaju različite projekcije grada, koji tokom tih procesa zadobija i različite, promenljive granice. Značenja koja mu oni pripisuju transformiše materijalnost samog prostora (Krauč 2002: 235).

Kada se posle urbanog performansa Klio $i$ Trepsihora, Tanja suoči sa emotivnim pražnjenjem, sa apokaliptičnim doživljajem sveta, briše suze, „ali one su se vraćale i rastapale grad, kuće od marcipana, mostove od kesten-pirea, parkove od mente. Sve se

1 Kontakt podaci (Email): ana.vukmanovic@hotmail.com 
ruši, mislila sam, sve se topi i nestaje" (Tasić 2004: 265). To mesto koje se topi najbolje opisuje kakav je Tasićev Novi Sad. On postoji u ljudima, mnogo je više unutra nego spolja, mnogo više konstrukt nego realan prostor.

Najstariji znak grada jeste zid, a on ne postoji samo u fizičkom smislu, već je najizrazitije simboličko obeležje grada (Doksijadis 1982: 278), utkano u njegovo poreklo. Takav omeđen prostor zadobija značenje celine, do te mere da u srednjem veku stvara i iluziju ostrva. ${ }^{2}$ Grad postaje autonomni svet, koji može predstavljati čitav kosmos. Gradske zidine trebalo je da odrede posvećene granice, da zatvore pristup zlim dusima više nego neprijateljski raspoloženim ljudima (Mamford 2006: 36-37). ${ }^{3}$ Zid, takođe, ističe razliku između onih spolja i onih unutra, između polja i grada (Mamford 2006: 70). Odbrambeno jedinstvo pretvara se u teskobu, strah, neprijateljstvo i agresivnost prema drugom (Mamford 2006: 325).

Druga oslona tačka urbane simbolike jeste pamćenje, koje ujedinjuje ono što je bilo i ono što će biti. U tom smislu grad je posuda za skladištenje i prenošenje poruka (Mamford 2006: 105). Obrisi i granice grada, kao i pamćenje o njemu, postoje u ljudima, likovima romana Kiša i hartija. Kroz estetski čin izgrađuje se višestruko složen konstrukt urbanog: to je kulturni konstrukt jer je grad tekovina kulture, svet koji čovek stvara, ali i umetnički, jer je deo umetničkog sveta pisca. Prostor nije samo organizovan i ustanovljen, on je isto tako oblikovan, njega prisvaja određena grupa u skaldu sa svojim zahtevima, etikom, estetikom, tj. svojom ideologijom (Lefevr 2005: 167). U Kiši i hartiji tu grupu čine romaneskni likovi. Oni su ti kroz čiju se vizuru konstruiše umetnički model Novog Sada. ${ }^{4}$

U umetničkom modelu sveta ili unutar urbanog konstrukta "gradovi se vide kao živa bića, sa plućima, krvotokom, licem, ponekim ogoljenim ramenom, otkrivenim detaljem koji naglašava i obećava; ne kao inkarnacija moći, kao sistem kamera i monumenata, betonskih erekcija i kanala čija je jedina svrha da usmeri i uplaši" (Tasić 2004: 141). Antropomorfna slika ističe ljudske doživljaje gradskog prostora, osećanja prema njemu, promene u odnosima koje su uslovljene vremenom i društveno-političkim promenama.

Ovakav urbani konstrukt podrazumeva etičku dimenziju koja biće uvek postavlja iznad moći. Rusoovski rečeno: kuće čine naselja, ali građani čine grad (Mamford 2006: 100). Pošto ljudi vrše transformacije u gradu, uspostavljajući svoj identitet, ulica nije jednostavno mesto koje se može prodati (Krauč 2002: 246). Shodno tome, centralni problem urbanog konstrukta u romanu Kiša i hartija predstavlja dvostruka pozicija Ijudi u gradu i grada u ljudima. Zato je Tasićev Novi Sad „obično mesto na kom su živeli neobični ljudi" (Tasić 2004: 267). Oneobičavanje se vrši kroz sećanja junaka, njihove razgovore i, na kraju, zajedničku akciju. Njihovo prisustvo postaje ključno za postojanje grada. Ono što čini odnos ljudi i grada dinamičnim, dijalektičnim jeste to što i grad

20 osećaju ostrva u srednjovekovnom gradu pisao je Luis Mamford (Mamford 2006: 325).

3 Mirjana Detelić, pak, smatra da zid, kuća, emanaciju svetog treba da zadrži unutra, u povlašćenom unutrašnjem prostoru (Detelić 1992: 133).

40 takvom složenom odnosu grada i književnosti piše Aleksandar Jerkov: „U gradu kao u idealnom mestu sve ostaje isto i sve postaje različito. Upisanost grada u tekst, urbana imaginacija otisnuta u književnim delima otkriva proces rađanja urbane poetike. Nije reč o opisima grada, već o simboličnom pečatu urbofilije" (1994: 655). Postojanje istog i različitog predstavlja suštinu estetskog konstrukta grada. On se referiše na stvarni grad, ali je od njega suštinski različit kao deo umetničkog sveta. Roman Kiša i hartija po načinu na koji tretira problem urbanog i po načinu na koji konstruiše slike grada u potpunosti pripada urbanoj poetici. 
postaje ključan za njih,jer: „Dok posmatramo, mi osvajamo svet, ali dok nas posmatraju, mi dobijamo svoje mesto u njemu" (Etikem/Lukinbil 2002: 202).

Predstava Novog Sada izgrađuje se iz prepletenih perspektiva petoro junaka: Tanje, Sonje, Nestora, Đure i Žorža. Na formalnom planu prave dijaloške forme gotovo da nema, a suštinski ona postoji u tom prepletu. Tanjinim posredovanjem prikazuju se različite vizure, iskustva i doživijaji, ali celina odaje utisak dijaloga, ili polifonije. Kiša i hartija zvuči mnoštvom glasova: iako nema dijaloške forme, postoji komunikacija. Polifonija se postiže kontrastnim slikama društva, sadašnjosti i prošlosti, u susretima, sukobima, unutrašnjim i spoljašnjim. Suštinu tog odnosa otkrivaju Tanjine reči: „Nismo se slagali u svemu; u tome smo bili kao jedan" (Tasić 2004: 25). Upravo slaganje o neslaganju obezbeđuje dijalog. Moguće je napraviti paralelu između forme romana i grada: grad svojom strukturom pruža mogućnost za sadržajni razgovor, ali se dijalog razvio uz teškoću jer je grad prvobitno počivao na monologu moći (Mamford 2006: 124). 0dnos među junacima nije obeležen odnosima moći, ali moć postoji kao društveni i politički fenomen, u predstavama promenjenog sveta, koje opterećuju junake, bez obzira da li se vraćaju iz (dobrovoljnog) izgnanstva devedesetih ili fizički nisu menjali mesto boravka.

Transformacije grada prate transformacije junaka. Kroz mnoštvo kontakata oni obrazuju svoj (urbani) identitet i menjaju ga. Izgrađivanje identiteta povezano je sa osećanjem pripadnosti. Ono je u junacima romana poljuljano: „0tkud nam ideja da negde pripadamo, da nam nešto pripada, čak i taj lavirint praznih hala, pogona zatvorenih fabrika, magacina sa razbijenim prozorima?" (Tasić 2004: 22). Odlazeći i vraćajući se, oni nose jedan grad u sebi, a drugi, i drugačiji, vide pred sobom. Unutrašnji grad je njihov, spoljašnji je tuđ. Unutrašnji je vezan za njihov identitet, spoljašnji podseća da je došlo do promena i u identitetu samom.

Veza između ljudi i grada gradi se na opoziciji svoje/tuđe, s tim što se taj mitski kontrast relativizuje, pa Tanja kaže: „Ovo je naš grad! Naša slatka laž, naša uteha” (Tasić 2004: 25). Svest o lažnosti utehe, pa time i prisvajanja grada otkriva moderni senzibilitetu kome ne postoje čvrste i nepomične tačke oslonca. Relativizacija se postiže aktiviranjem istorijskog nasuprot mitskom vremenu. Žorž „je tražio mesta na kojima je ranije, dok je još poznavao svoj grad, mogao da sretne sanjare, duvače, svirače, pripovedače, strip crtače, ludake koji još uvek vole tu varošicu na steroidima, vole je dovoljno da o njoj raspredaju povesti i legende, da po njenim zidovima ispisuju nerazumljive poruke..." (Tasić 2004: 71). U takvoj poziciji svoj grad ne postoji, on je ili deo prošlosti, ili, još više, legende. Potvrđuje se da je odrednica svoj jednako konstrukt kao i grad sam. Lirska predstava nepostojećeg mesta kao kuće posebno je prisutna u Tanjinom pripovedačkom komentaru Žoržove priče: „To je bio naš grad, naša kuća. Kao kada se deca igraju, jedno vreme čuče skrivena iza stabala, buradi, automobila, a onda pojure ulicom uz ciku i neka od njih zadihano dotrče na mesto koje im u mašti i konvenciji igre pruža sigurnost, skoče na njega i uzviknu: kuća! Ko zna koja po redu" (Tasić 2004: 78). Sigurnost gubi stabilne oslonce, pretvarajući se u dečji svet, grad postaje mesto iz mašte. ${ }^{5}$ Tasić lirskim sredstvima slika ljudsku nesigurnost u svetu i dočarava egzistencijalni strah.

5 Vladan Desnica u romanu Proljeća Ivana Galeba, pišući o sumnji u realnost realnog, beleži: „Doista, zar i fakat našeg doživljavanja u misli, u fantaziji, zar i fakat našeg čuvstvovanja, treperenja naše senzibilnosti, nisu isto tako fakti kao i oni vanjski" (Desnica 1967: 132). 
Opoziciju svoje/tuđe dodatno relativizuje opozicija staro/novo. $S$ jedne strane, prošlost je obeležena kao vreme sreće, spokojstva, pripadnosti, sigurnosti, pa nestanak starih mesta prati melanholija. Međutim, Žorž je sam postao „željan novog početka, početka koji bi bio kraj svih početaka, željan novog prostora, novog grada, nekog novog sada u kojem bi se, paradoksalno, mogao smiriti, skrasiti" (Tasić 2004: 50). Tako se potreba za odlaskom, za novim početkom ne motiviše samo istorijsko-politički, u kontekstu' 90 -ih godina 20 . veka, već i egzistencijalno i psihološki iz pozicije čoveka kao pojedinca. Upravo iz te humanističke pozicije Tanja zaključuje da se grad posle njihovog performansa promenio jer oni više nisu bili isti (Tasić 2004: 263). Konstrukt se menja zajedno s promenom tačke gledišta, konteksta i promenom onih koji ga stvaraju. Kako se menjaju likovi, menja se i Novi Sad.

Važnu dimenziju doživljaja grada nesumnjivo predstavlja istorijsko-politički kontekst. Sonja objašnjava Žoržu „da je grad drugačiji, da su mnogi otišli, da ih se malo vratilo, ali da nije sve propalo; da postoje određena mesta, zanimljivi ljudi" (Tasić 2004: 75). Svojim iskazom ona stvara konstrukt vremena: sadašnjost (početak 21. veka) određuje kao negativno promenjenu, ali ostavlja "mogućnost ostrva”, predstavljenog u preživelom urbanom duhu. Istorijsko vreme postaje apokaliptično u Žoržovom strahu da „možda postoji samo đubre, svemoćno i sveprisutno, đubre koje i jeste grad, trag koji ostavljamo za sobom kao jedini važeći dokaz postojanja, jedina istorija koja se, doslovno, broji" (Tasić 2004: 48). Posle iskustva s kraja 20. i početka 21. veka, kroz moderno osećanje gubitka iluzija, svet se izjednačava sa đubretom, i u fizičkom i u metafizičkom smislu, a utehe ili nema ili je himerična.

Tanjine reči: „Grad se polako praznio. Ili, ne. Nije se praznio. Nestajali su ljudi koje sam poznavala; pojavljivali su se drugi, nesrećniji. Dešavalo se da izađem i ne sretnem nikog poznatog" (Tasić 2004: 140) ukazuju na isti pristup gradu, na nelagodnost pri susretu sa drugačijim i potrebu za poznatim, svojim.

Likovi se postavljaju u dijaloški odnos sa gradom kao mestom-sastajalištem, na kom dolazi do „mešanja rasa, kultura i tehnologija, do biološke hibridizacije. Grad pruža otvoren pristup strancima iz spoljnog sveta" (Mamford 2006: 102-103). Na gradskim vratima sastajala su se dva sveta, gradski i seoski, unutrašnji i spoljašnji (Mamford 2006: 325). Dolazi do kontakta, ali oni nisu jalovi samo u susretu sličnog sa sličnim (zanimljivi ljudi). Različiti se ne razumeju, ne dele svet. Istina grada je prilika za zajednički život s nepoznatim. Grad čini susret neizbežnim, što donosi neprijatnost (Jerkov 1994: 657), čak i kada je susret sa drugim bićem određen kao susret sa nepoznatim u kome nema ničeg strašnog i pretećeg.

Nasuprot idealizovanju grada kao mesta interkulturalnosti, u kome različite osobe i načini života, stavljeni jedni pored drugih, mogu da pruže relativističku perspektivu i osećanje tolerancije za razlike (Virt 2005: 120), moguće je i da potencijalna razlika među ljudima postane tim veća što više pojedinaca učestvuje u procesu interakcije. Takve varijacije podstiču različite vrste segregacije (po kulturnom nasleđu, ekonomskom i društvenom statusu, ukusima) (Virt 2005: 117).

Ljudski kontakti su važni još u jednom aspektu konstruisanja prostora. Vesti u gradu se, zapravo kao i u selu, prenose tako što „uvek ima nekog ko poznaje nekog ko poznaje nekog ko zna, i vest se, kao u igri gluvih telefona, širi i preobražava" (Tasić 2004: 10). Šireći se, vest organizuje i urbani prostor, postavlja imaginarne granice. Kada 
Tanja komentariše na koji način su vesti (ili glasine) o njihovom performansu dolazile iz različitih delova grada, kaže: „Vesti iz drugih krajeva grada u početku su stizale sporo, sa pešacima, skejterima i biciklistima koji su uspevali da se probiju kroz saobraćajni kolaps nastao usled prestanka rada semafora. Uskoro je, međutim, ulogu kurira preuzela trojka motorizovanih huligana [...]za mene su bili glasnici doba dezinformacija[...] Vesti koje su prenosili do nas su stizale iz druge, treće, ili ko zna koje ruke, i zvučale su, rečju, fantastično" (Tasić 2004: 255-256). Te vesti koje zvuče fantastično odgovaraju fantastičnom gradu nastalom u umetničkom izvođenju, i onom unutrašnjem koji ljudi nose u sebi.

Čovek formira urbani konstrukt i svojom sposobnošću kretanja, koja je „prirodni i univerzalni jezik ljudskog bića" (Tasić 2004: 18). Od početka istorije grad se određivao kinetičkim poljem čoveka koji je bio u stanju da se kreće i stvori svoje mesto za život (Doksijadis 1982: 111). Taj kinetički grad u Kiši i hartiji formira se na više nivoa. Tanjin otac pokazuje da sa kćerkom deli isti (imaginarni) prostor timešto zna koliko joj vremena treba od radio stanice do kuće, što zna da će ona ići okolnim putem. ${ }^{6}$ Posebne mape grada stvaraju se nabrajanjem urbanih uporišnih tačaka pored kojih likovi prolaze. Tako Tanjin otac zna da će ona proći „pored pozorišta za decu, neke ruševine koja će tamo ostati godinama, decenijama, prema ulici s papirnicama i poslastičarnicama na čijem je početku bio dvorac boje breskve, da [će] proći kroz pešačku zonu, svratiti u prodavnicu ploča na trgu, preći na suprotnu stranu i zastati pred bioskopom koji će docnije postati tržni centar, i da [će] posle toga, posle te avanture, krenuti pravo kući" (Tasić 2004: 13). ${ }^{7}$

Čovek koji se kreće izgrađuje mikrokosmos, u odnosu na njegov položaj odrednice blizu i daleko, ovde i tamo dobijaju smisao, one postaju ja iskazi. Figura flâneura u Kiši $i$ hartiji nije polno određena. To može biti Žorž, ali i Tanja. U tom smislu šetač se udaljava od svog istorijskog značenja, ali glagol skitati nastavlja da opisuje istraživanje urbanih prostora; hodanje bez neke određene putanje. Skitnja promišlja grad kao mogućnost za kontinuirano kretanje, a ne niz diskretnih arhitektonskih elemenata. Prostori skitnje ostaju mesta dokolice, zadovoljstva, potrošnje, razmene i pokazivanja. Društvene relacije prostorno su artikulisane - kroz prostor i mirovanje i vizuelno - kroz veze između posmatrača i posmatranog (Rendal 2002: 110). Pozicija šetača u romanu se usložnjava na imaginacijskoj ravni. Kada Tanja kaže: „Putovaću bez kretanja, nepomična u svojoj pećini" (Tasić 2004: 266), onda skitnja dobija interiorizovanu dimenziju. To putovanje bez kretanja postaje lik u ogledalu kretanja kroz grad, posebno kada se ima na umu da nam pisaci grad sâm predstavlja kao unutrašnju sliku.

Osim hodom, urbana mapa se stvara i vožnjom. Kompletna slika, potpuni doživljaj dobija se upravo u prepletu različitih kretanja. Složenost pokreta i mapa čini prostor urbanim: „Bulevarom se kretao karavan vozila i mopeda, brodovi-restorani ljuljali su se na talasima, kejom su hodali penzioneri, parovi, deca, čitav jedan pešački grad čiji su ritam povremeno presecale devojčice na koturaljkama, skejteri, biciklisti i psi koji su njušili, jurili mačke ili jedni druge" (Tasić 2004: 246-247).

6 To što dele isti grad, utiče na njihove svakodnevne živote, na prepoznavanja i skrivene bliskosti, nežnosti. Zato što otac zna njene putanje, nju čeka ugrejano mleko kada se vrati kući (Tasić 2004: 13).

7 Svoju mapu grada pravi i Žorž nabrajajući tačke oslonca ili samo urbane tačke pored kojih prolazi kada krene prema kući (Tasić 2004: 72-73). 
Radnja se u romanu odvija ina otvorenom (kretanje kroz grad ili urbani performans) i u unutrašnjim prostorima (stan, kafe-knjižara). Međutim, sam pristup gradu je interiorizovan, jer je individualizovan, provučen kroz matricu sećanja i doživljaja. S druge strane, $u$ urbanoj akciji on postaje otvoren jer prevazilazi prostorne granice i određenje grada kao zatvorenog, zidom ograđenog, prostora. Konstruktivistička poigravanja sa dimenzijama i odrednicama unutra/napolju vidljiva su u Tanjinom opažanju galebova: „Negde u beskrajnom prostoru koji je ipak dovoljno mali da se može obuhvatiti rečju napolju, galebovi su kliktali, uzletali i ponirali, kružili nad nečim. Ako bih svet pogledala s njihove visine, videla bih igračku" (Tasić 2004: 8). Upravo spoljašnji, neomeđeni prostor postaje dovoljno mali, što može implicirati da se unutrašnji prostor vidi kao širok, veliki, bezgraničan. Inverzija binarnog para upućuje na moderni doživljaj sveta u kom je težište na subjektivnim, pa i virtuelnim svetovima.

Binarni par centar/periferija određen je ideološki. Kada izvode performans nedaleko od centra grada, na reci, mostu, junaci Kiše i hartije nalaze se na periferiji ne toliko prostornoj (iako je voda u mitskom smislu liminalni prostor prvog reda) koliko socijalnoj. U određenim društveno-političkim prilikama njihova kultura je subkultura. Lefevr (2005: 169) kaže da se centar razara zato što odbija drugu centralnost, razara se ukoliko proizvodi akciju onih koji isključuju i teraju ka periferiji. Segregacija čini teorijsku i praktičnu negaciju urbanog. Junaci romana deluju iz pozicije isključenosti, marginalnosti. Međutim, oni ne izazivaju promene u centru. Njihova akcija je romantičarskog tipa - ona je efemerna, lirska, njihov grad se rastapa u suzama kao kuće od marcipana. Njena snaga je, poput snage performansa koji se izvodi samo jednom, u kratkotrajnosti i neponovljivosti. Centar i periferija postaju relativni, jer se nalaze u ljudima, ne u realnom prostoru. ${ }^{8}$

Tasićev grad je mesto heterotopije, on spaja kontrastne prošle i sadašnje prostore, prostore različitih estetika i etika. Iz perspektive Lehanove podele na centripetalan (naturalistički) grad, u kom se život kontroliše iz centra urbane sile, i centrifugalan (modernistički), gde se centar pomera ka simboličkim vezama u prostoru i vremenu (Panić Maraš 2010: 64), romaneskni Novi Sad bi pripadao drugom tipu. Urbana sila u njemu dolazi s periferije, pa se konstrukt urbanog centra formira u simboličkom prostoru i vremenu, u ljudima i umetničkoj akciji.

Deo urbanog konstrukta takođe je i čulni grad. U prepletu različitih mirisa, mirisa na sneg koji nije pao, prženo kestenje i kokice, spajaju se priroda i kultura, obe obeležene pozitivno, dok različita sećanja i različite stvarnosti prate kontrast između mirisa snega, kestenja i kokica s jedne strane i asfalta i smeća koje se preliva iz prepunih kontejnera, s druge. Čulni nadražaji se oblikuju kroz prizmu doživljenog, čime im se oduzima objektivnost. Oni postaju deo osećanja marginalnosti savremenog čoveka.

Najsnažniji čulni doživljaj u Kiši i hartiji obezbeđuje ritam. On se izdvaja unutar performansa Klio i Trepsihora, koji integriše različite medije. Unutar estetike spajanja slike, zvuci, pokreti, radnje spajaju se elektronskim vezama sa živim telima, stvarajući

8 Doksijadis ukazuje na to da savremeni grad ima više centara koji se stalno menjaju. To je dinamičan grad dinapolis (Doksijadis 1982: 281). Svetski grad više neće imati centralnu tačku. Postojaće centri višeg i nižeg reda (Doksijadis 1982: 299). U Kiši i hartiji se ne postavlja problem velikog grada, Novi Sad je još uvek samo varošica na steroidima, već je pitanje centra i periferije povezano sa egzistencijalnim pozicijama junaka. 
heterogeni sklop, koji se može pretvoriti u mimezis elektronizovane stvarnosti (Jovićević/Vujanović 2006: 258). Elektronska muzika, pomoću skenera i kamera beleži ritmove grada: „ritmove poziva, poruka, sastanaka, rastanaka, crvenih i zelenih talasa, plima i oseka saobraćaja, ritmove raspoloženja, uličnih svetiljki, redova vožnje, ciklusa pekara, praznika, svetkovina, izbora, proslava, vesti i serija, postova i slavskih bahanalija, radnog i slobodnog vremena, ritmove kafea, stambenih galaksija, godišnjih doba, dana i noći, rođenja i sahrana, numerisanih virova i dalekih satelita" (Tasić 2004: 241). U tom modelovanju ritma spajaju se realni grad i urbani konstrukt, stvarnost i umetnost, dva sveta. Ritam postoji oko ljudi, i u njima. Ritmički prepleti odgovaraju i dvama gradovima: onom pothranjenom u mrežama Žoržovih računara (i u junacima samim), po kojima bi svaka zgrada, raskrsnica, fasada, mogle biti po potrebi rekonstruisane, i onom koje te zgrade, raskrsnice i fasade čine u istorijskom vremenu.

Drugi dvostruki izvor ritma čine građevinske mašine i Nestorov snimak, koji sam ritamski izvor preoblikuje: „Ritam građevinske mašine najednom je postao drugačiji. Bio je svuda oko nas, odjekivao je, činilo mi se, čitavim gradom. Pojačavao se i zatim se u začaranom krugu utapao u bezbrojne kopije sebe (...) i sada su svi ti ritmovi, različiti ali isti, postajali nešto drugo, nešto moćnije" (Tasić 2004: 249).

Elektronski uređaji beleže kretanja ljudi, sabiraju ih i pretvaraju „u zaglušujuću buku hiljade glasova koji pevaju, uzdišu, izdišu, smeju se, mucaju, prete, ustaju, šapuću, preklinju, krkljaju, žale se, hvale se, kikoću se, jecaju, grcaju, mrmljaju, rade sve što glasovi rade na trista različitih jezika, i taj haos se prenosi gradom kao krugovi na vodi, a zatim se vraćaju i u sudaru i suočenju sa sobom postaju nešto novo, jeziva i zadivljujuća simfonija u kojoj most zvuči kao vozovi[...]" (Tasić 2004:253). ${ }^{9}$ Kao osobenost urbanog savremenog grada izdvaja se spoj tehnike i tehnologije sa humanitetom. Upravo one, osuđene kao uzroci otuđenja, dovode do suočavanja sa izvornim i duboko egzistencijalnim zvucima i stanjima čoveka, sa njegovim najintimnijim unutrašnjim svetom.

Iz te disharmonije „naposletku se uzdigao krik, užasan akord, ili disakord koji nije popuštao već je neprestano uzlazio, preobražavao se, nadletao grad nošen zvučnicima i cvećem, kroz bašte, parkove, groblja, penjao se u bolnom glisandu" (Tasić 2004: 250-251). Iz ritma nastaje egzistencijalni, munkovski krik, a slika grada postaje deo promišljanja čoveka u apokaliptičkom trenutku. Kao što postoje ritam grada i ritam performansa, tako postoje i krik čoveka i umetnički krik: grad i čovek se iznova stapaju u jedno unutar misli o postojanju i nestajanju. Umetnost im pak nije suprotnost, već je deo njih, kao drugo lice istog organizma. ${ }^{10}$

Metamorfozu tog krika čini jednako važan uzdah koji Tanja čuje: „simultani uzdah mirijade duša, blistavih ili ukaljanih, hropac ili olakšanje, što je brzo zamenio šum uzbuđenih glasova praćenih ritmom koji se ustalio, ustrajavao i pulsirao kroz kosti" (Tasić 2004: 251). Učešće ljudi u doživljaju preformansa uspostavlja veze neophodne za postojanje grada. Konstrukt urbanog se formira u komunikaciji i interakciji, a u ovom slučaju u zajedničkoj graničnoj egzistencijalnoj situaciji.

9 Za američkog kompozitora Džona Kejdža ono što čujemo, gde god se nalazili, uglavnom je buka, koju treba uhvatiti, kontrolisati i transformisati u muziku (Jovićević/Vujanović 2006: 165).

10 Pomenuti spoj prirode i kulture sreće se i u umetničkoj intervenciji postavljanja kalema u cveće tako da se stabljika i latice koriste kao zvučnik. 
Vizuelni deo performansa obezbedile su digitalne kamere koje su, postavljene na bilborde, snimale pokrete grada dvadeset četiri sata na dan. Čitav grad je bio platno, skup pozornica na kojima se odigravaju nevidljive drame, crni prostor. Ljudi „na ekranima bilbordâ vide svoj grad, na svakom ekranu upravo onaj deo pejzaža koji je inače zaklonjen tričarijama na reklamnom panou a sada ga pokazuje kao što bi ga prikazalo okno velikog prozora po čijoj se površini sliva olujna kiša, moćna, u velikim kapima" (Tasić 2004: 251). 0tkrivanje zaklonjenih pejzaža jeste reakcija na promenu grada, na izgradnju tržnih centara, prodavnica, turističkih agencija, crkava, banaka na mestu magacina, mestu koje ima sentimentalno značenje, koje je deo nečijeg grada, nečijih života. Bilbordima sa otkrivenim gradskim pejzažem kaže se „ne" pripitomljavanju gradskih ulica u savremenom merkantilnom okruženju (Džekson 2002: 252). Prisvajanje javnog prostora označava ideološki stav: komodifikacija može da prisvoji naša sećanja, znanja, načine na koje se poslovi obavljaju (Krauč 2002: 245). ${ }^{11}$ Hana Arent smatra da su izvođačke umetnosti bliske političkom delovanju jer, da bi se realizovale, zahtevaju organizaciju javnog prostora (Jovićević/Vujanović 2006: 290). Tako performans Klio $i$ Trepsihora predstavlja odgovor modernog iskustva na sve jaču regulaciju i kontrolu javnog prostora i organizuje gradski pejzaž na nov način, modelujući stvarnost i grad.

Hronotop grada u noći nosi posebna simbolička značenja. Performans iz Kiše $i$ hartije može se uporediti sa provokativnim plakatima i grafitima koji se u gradu pojavljuju tokom noći. Oni su alternative rečima koje se javljaju tokom dana i sugerišu da je diskurs noći možda poslednji oblik političke debate (Kresvel 2002: 370). U tom kontekstu grad se ponovo otkriva kao složen, u najmanju ruku dvostruk: ulica je mesto i znak dominacije i reda, ali i mesto i znak nemira, nereda i pobune (Kresvel 2002: 371). Klio i Trepsihora je kao aktivistička umetnost tu da je svi vide. Ona egzistira na otvorenom, u gradu. Ne može se kupiti, zapravo ceo koncept se raspada pri pokušaju poslovnih pregovora sa kompanijom Pepsi.

$S$ druge strane, instrumentalizacija prostora, bez obzira $s$ koje pozicije se dešavala, „omogućava segregaciju društvenih grupa, funkcija i mesta” (Lefevr, prema Vujović/Petrović 2005: 40). Rušenje magacina simbolički izopštava iz grada junake romana, ali i njihov performans isključuje one koji se za rušenje zalažu (čak i ako nisu imenovani).

Osobenu urbanu mrežu obrazuju različiti svetski gradovi. Veze mogu biti asocijativne, vezane za ojkonime: Njujork - Nju Delhi - Novi Sad. Mogu se zasnivati i na vizuelnim sličnostima, kakva postoji u betonskoj arhitekturi Praga 12 (ili 13) i Limana II. Značaj te mreže leži u konceptu svetskog grada i mogućnosti promišljanja sličnosti i razlika između različitih urbanih naselja širom planete. Poređenja se mogu ticati vizuelnih identiteta (arhitekture i urbanizma), ali i društveno-političkih, kulturnih i egzistencijalnih problema. Površne asocijacije omogućavaju dublja promišljanja urbanog konstrukta.

11 Paralela zloupotrebe javnog prostora sreće se i u Rimu tokom fašističke vlasti. Delovi grada bili su porušeni i zamenjeni širokim, modernim, monumentalnim avenijama, koje su postale idealna mesta za fašističke parade i spektakl, kao i za bolji saobraćaj (Etkinson 2002: 38). Stvarajući tipske totalitarne ulice, režim je uništio četvrti stvorene u proteklih nekoliko vekova, u kojima su obitavale davno formirane zajednice (Etkinson 2002: 43). 
Slike grada u romanu Kiša i hartija potvrđuju stav da urbano društvo nije završeno, već da se stvara (Krauč 2002: 166). Promene u gradu, koje se dešavaju kroz istoriju, ali i u savremenom trenutku, i u junacima, od presudne su važnosti za izgradnju urbanog konstrukta. Bez svesti o promeni, o transformacijama i dinamici nema svestio urbanom. Ta promenljivost omogućava i multifunkcionalnost, kao još jednu od ključnih uloga u uspostavljanju gradskog života. Polifonom organizacijom romana unutar glasa jednog dramatizovanog pripovedača, različitim istorijskim linijama radnje, postavljanjem prostora grada u centar pažnje forma romana Kiša i hartija omogućila je sagledavanje složenih mehanizama formiranja konstrukta urbanog u svesti junaka, u umetničkom svetu dela i u kontekstu savremenih promišljanja fenomena urbanog.

\section{LITERATURA}

Desnica, V. 1967. Proljeća Ivana Galeba. Beograd: SKZ.

Detelić, M. 1992. Mitski prostor i epika. Beograd: SANU.

Doksijadis, K. 1982. Čovek i grad, prev. M. R. Perović. Beograd: Nolit.

Džekson, P. 2002. Pripitomljavanje ulice. Konfliktni prostor glavne ulice i tržnog centra. U N. Fajf (ur.) Prizori ulice, prev. I. Šentevska. Beograd: Clio.

Etikem, S. i K. Lukinbil. 2002. 0 herojima, ludama i kraljevim ribama. U N. Fajf (ur.) Prizori ulice, prev. I. Šentevska. Beograd: Clio.

Etkinskon, D. 2002. Totalitarizam i ulica u fašističkom Rimu. U N. Fajf (ur.) Prizori ulice, prev. I. Šentevska. Beograd: Clio.

Jovićević, A. i A. Vujanović. 2006. Uvod u studije performansa. Beograd: Fabrika knjiga.

Jerkov, A. 1994. Antologija beogradske priče II. Beograd: Vreme knjige.

Krauč, D. 2002. Ulica u stvaranju popularnog geografskog poimanja. U N. Fajf (ur.) Prizori ulice, prev. I. Šentevska. Beograd: Clio.

Kresvel, T. 2002. Diskurs noći. Proizvodnja/potrošnja značenja na ulici. U N. Fajf (ur.) Prizori ulice, prev. I. Šentevska. Beograd: Clio.

Lefevr, A. 2005. Urbanizam kao način života, prev. S. Vujović. U M. Petrović i S. Vujović (ur.) Urbana sociologija. Beograd: Zavod za udžbenike.

Mamford, L. 2006. Grad u istoriji, prev. V. Ivir. Beograd: Book Marso.

Panić Maraš, J. 2010. Grad i strast. Beograd: Službeni glasnik.

Petrović, M. i S. Vujović (ur.) 2005. Urbana sociologija. Beograd: Zavod za udžbenike.

Rendal, Dž. 2002. Iskazivanje seksualnosti: Polni identitet i ulica ranog 19. veka. U N. Fajf (ur.) Prizori ulice, prev. I. Šentevska. Beograd: Clio.

Tasić, V. 2004. Kiša i hartija. Novi Sad: Svetovi.

Virt. L. 2005. Urbanizam kao način života, prev. J. Kovačević. U M. Petrović i S. Vujović (ur.) Urbana sociologija. Beograd: Zavod za udžbenike. 


\section{SUMMARY}

\section{THE URBAN CONSTRUCT IN THE NOVEL KIŠA I HARTIJA BY VLADIMIR TASIC}

The urban construct formed in Tasić's novel Kiša i hartija is a cultural and aesthetic construct. In connection to the main characters, the urban space around them also shows that it affects their identities. They occupy positions within the contrasting oppositions my own/somebody else's and old/new. An urban construct is formed through the communication between characters and through their own self-observations. The oppositions outdoors/indoors and, especially, centre/periphery mark the significance of movement for the images of the city. Urban images also have an existential meaning, particularly those connected with the performance Clio and Terpsichore, in which the city rhythm and an existential human cry are united. The visual layer of this performance contributes to pondering over the problem of claiming the right to the city.

KEYWORDS: city, construct, performance, communication, identity.

(Originalan naučni rad primljen 30.11.2011; ispravljen 03.01.2013; prihvaćen 03.01.2013) 